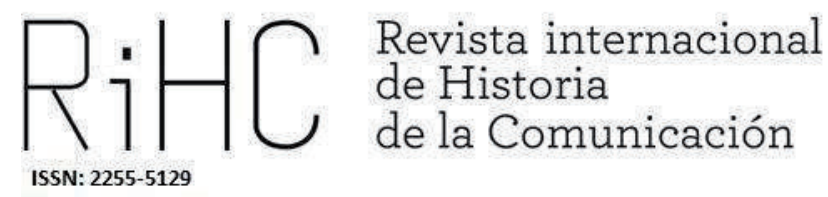

\title{
COMUNICACIÓN, FEMINISMOS Y GENEALOGÍAS DE GÉNERO EN LA PENÍNSULA IBÉRICA
}

Communication, feminisms and gender genealogies in the Iberian Peninsula

Comunicação, feminismos e genealogias de gênero na Península Ibérica

DOI: http://dx.doi.org/10.12795/RiCH.2021.i16.01

Ana Cabrera

Universidade Nova de Lisboa, Portugal

anacabrera@fcsh.unl.pt

ORCID (D) http://orcid.org/0000-0002-2372-5165

Ma Teresa Vera Balanza

Universidad de Málaga, España

teresavera@uma.es

ORCID (D) https://orcid.org/0000-0002-3089-4469 
Este monográfico nace de la colaboración y de la necesidad de recomponer una situación insólita en la investigación científica en general y en la de la comunicación en particular. Si para cualquier campo del conocimiento es preceptivo la perspectiva comparada y la correlación de resultados en contextos similares, en la Península Ibérica la anomalía resulta patente.

En este momento del siglo XXI, y dentro de las coordenadas de la Sociedad de la información y el Conocimiento, se propone un abordaje del ecosistema comunicativo ibérico (Sierra Caballero, 2008), si bien explorando dos nuevas dimensiones: una, la de implementar la perspectiva de género; otra, la de nutrir una línea temporal amplia en las relaciones bilaterales desde los inicios de la contemporaneidad. El resultado es un panorama que se amplifica en el tiempo y se incrementa en la diversidad de agentes. Adicionalmente, también se proponen lecturas convergentes sobre trayectorias o temáticas paralelas, análisis sobre producciones transnacionales, o profundizaciones sobre etapas históricas de transformación o transición donde emergen las nuevas imágenes o representaciones mientras perviven, paradójicamente, las rémoras y las tradiciones.

En lo que refiere a los sujetos, las dinámicas socio demográficas han generado el relevo generacional en la participación y en la acción política, en las profesiones vinculadas a la comunicación y la cultura, y en la sociedad toda para evidenciar la mayor presencia y participación de las mujeres. Sin embargo, el crecimiento exponencial presenta deficiencias referidas a las oportunidades, a los modelos de liderazgo $y$, consecuentemente, a su presentación y representación comunicativa. La fundamentación teórica y conceptual de esta situación tiene una doble filiación. Una durante la segunda ola del Feminismo y a partir de las conclusiones a la Mística de la feminidad, el texto paradigmático de Betty Friedan (2009), cuando planteaba: "Y desde entonces, en tiempos de cambios, cuando abordo preguntas que nadie se ha planteado, que es preciso hacerse, siempre me interesa comprobar si la imagen comúnmente aceptada que ofrecen los medios de comunicación encaja o no con la realidad de las vidas de las mujeres...." o en otras palabras, si los medios acompañan los cambios, los ralentizan o los ignoran. Otra, a partir de la década de los 90 y a propósito de las disquisiciones críticas sobre la construcción del género, la sexualidad y la raza, fundamentados por Teresa de Lauretis (1990) haciendo uso de la noción foucaultiana de biopoder, para redefinir la representación cinematográfica, artística y científica en términos de tecnologías del género. Esta concreción de las relaciones de poder en el mundo contemporáneo tiene en los medios, los relatos y los discursos comunicativos su escenario preferente y así lo han suscrito las contribuciones de este monográfico.

El paralelismo histórico entre Portugal y España ha sido objeto de la Historia, de la Política, de la Literatura también, pero entendemos que todavía no se ha explorado 
suficientemente desde la Comunicación -salvo el Monográfico no 112018 RiHC en un doble hándicap si entendemos que la comunicación tiene por sentido el entendimiento o, al menos, la comprensión.

Los hitos contemporáneos que nos aproximan como las dictaduras contemporáneas, el establecimiento de la democracia y la adhesión a la Comunidad Europea, obvian una ligazón aún más profunda y anterior en el tiempo, que entronca con el pensamiento republicano y con las tradiciones emancipatorias. Ello es fundamental para entender los factores endógenos y exógenos que en el pasado vincularon a las feministas y a las organizaciones de mujeres, que reforzaron la participación de las mujeres en la oposición antifascista y que sustentaron las políticas públicas por el desarrollo de los derechos de las mujeres y en la lucha por la igualdad entre hombres y mujeres. También es definitivo, de cara al futuro, para proyectar una posición relevante ante Europa y con respecto a América Latina y a África, en el sentido de puente entre territorios extensos; las referentes, nuestras antepasadas, algunas de las que aquí se retratan, ya lo hicieron adelantándose incluso a hablar de mestizaje, de pacifismo, de utopías globales. Queremos que sus enseñanzas y sus trayectorias vitales no queden en la ignorancia o el olvido cuando más falta hace tenerlas presentes.

Transitar el siglo XXI y la Sociedad del Conocimiento desde la condición de ciudadanía en todas sus acepciones (de la política a la digital), exige el abordaje de los retos como la globalidad de las acciones y los usos empoderados de las tecnologías pero también una mirada retrospectiva y un compromiso de reconocimiento que valore el papel de quienes antes, como ahora, tomaron la palabra, utilizaron las tribunas, accedieron al debate público y reclamaron para sí y para otras y otros, derechos y libertades.

A esta llamada han respondido un considerable número de aportaciones a las que agradecemos su generosa contribución; finalmente nos acompañan once propuestas procedentes de las universidades de Extremadura, Católica de Murcia, Valladolid, Sevilla y Málaga en España; Nova de Lisboa, Coimbra, Oporto y Universidade Catolica portuguesa, Universidade Lusófona, en Portugal; y también una propuesta desde la Universidad de Lille en Francia. Son muestra de un interés pero también de un territorio por explorar, una reorientación del enfoque $y$, tal vez, de una mirada periférica sobre un asunto al margen de los itinerarios hegemónicos.

Elena Benítez Alonso, de la Universidad de Sevilla, nos invita a reconocer el trabajo de las autoras que iniciaron su actividad profesional mediante la crónica de sociedad, entendida como una parcela "amable", ideológicamente poco comprometida, pero intensamente fructífera en clave socioeconómica y en construcción de estereotipos de género y clase. La autora nos propone la visibilización del papel de la mujer como

1 GUILLAMET LLOVERAS, Jaume (2018): “Presentación dossier Medios y transiciones", en Revista Internacional de Historia de la Comunicación, no 11, pp. 1-4. 
cronista de sociedad en los albores de la prensa inglesa decimonónica. Actualizada a partir de la serie de televisión Los Bridgerton, producida por la plataforma Netflix, cuya trama se sustenta sobre los epistolares society papers de Lady Whistledown, un personaje de ficción que se nutre de referentes históricos y que avanza también la participación de literatas, reporteras, periodistas que iniciarán de este modo, su actividad profesional en la prensa. Es el caso de Mrs. Crackenthorpe, columnista inglesa de principios del siglo XVIII especializada en los ecos de sociedad, que recogía desde The Female Tatler. Coetáneamente, a mediados del XVII La Pensadora Gaditana, Beatriz Cienfuegos, también observa y narra la crónica de la alta sociedad española. Elena Benítez nos muestra a las autoras que, ya avanzado el XIX, desarrollan su labor informativa en la prensa sevillana, donde encontramos notorias firmas, como la de la Condesa de Bassanville o la de Fernán Caballero, y que nutren toda una galería, generalmente dispersa y escasamente conocida, pero fundamental en la historia y también en la estructura financiera de la prensa contemporánea.

Teresa Vera y Rosa Ballesteros de la Universidad de Málaga proponen un diálogo en torno a las relaciones de sororidad entre coetáneas lusas y españolas en el primer tercio del siglo XX. Las biografiadas no solo crearon redes de colaboración en la actividad política, viajaron y estrecharon relaciones con colegas latinoamericanas y europeas, y fundaron foros de organización política en la línea republicana y emancipadora; algunas, además, desempeñan profesionalmente el periodismo como actividad complementaria del ejercicio de la ciudadanía. Así el movimiento de mujeres que a los dos lados de la frontera se va configurando durante los siglos XIX y XX confluye con el acceso a una profesión que permite, a la vez, denunciar las desigualdades y difundir la educación de las mujeres como mecanismo para solventar la situación de injusticia social que acontece en ambos estados y que afectaba, aún más, a las mujeres de las clases populares. Las trayectorias personales y profesionales de estas antecesoras presentan relevantes similitudes y nutren una genealogía propia que se incorpora tanto a la línea activista a través de las experiencias de Adelaide Cabete y Carolina B. Ângelo; como a la periodística que aglutina a varias de las profesionales hispanas y lusas, especialmente a través de la relación entre Ana de Castro y Carmen de Burgos, generadoras de toda una constelación de profesionales de la comunicación que incluye a periodistas, reporteras, cronistas, que son modelos y referentes hoy en día.

María Arroyo Cabello de la Universidad Católica de Murcia nos presenta a otra pionera María Luz Morales Godoy, la primera mujer en España que dirigió un gran diario nacional, La Vanguardia, al inicio de la Guerra Civil Española (1936-37). Previa a esta tarea ejecutiva, la periodista fue una precursora del periodismo cultural y su prolífica obra la convierte en un referente en la historia del periodismo. El artículo se sustenta sobre la recopilación de las crónicas tituladas Charlas y publicadas en la sección "La Mujer, el Niño y el Hogar» de El Sol entre 1926 y 1931. El análisis del contenido de estas crónicas constituye todo un repertorio de las pautas de socialización de las mujeres en 
un periodo de transformación, así aunque los temas coinciden con los contenidos habituales de las revistas femeninas, sin embargo, difieren en el enfoque. El eje temático de las crónicas gira en torno a la literatura escrita por mujeres, literatura infantil, lectura, teatro y moda, coincidiendo en ese afán pedagógico con la línea iniciada por las predecesoras de la segunda mitad del siglo XIX. La autora fomenta la promoción cultural de la mujer y reclama para ella una consideración intelectual de igualdad.

José Cândido de Oliveira Martins de la Universidad Católica Portuguesa, presenta en su artículo a tres escritoras portuguesas, Maria Judite de Carvalho, Agustina Bessa-Luís y Maria Teresa Horta, todas ellas involucradas en el periodismo, por medio de sus crónicas divulgadas en la prensa. Tras rastrear el encadenamiento político, social y periodístico de los últimos años del Estado Novo, el autor añade la larga vigencia de la censura, la clausura de la sociedad portuguesa, empeorada, además, por la guerra colonial. En este contexto, el objetivo del autor consiste en analizar la colaboración de escritoras en la prensa de aquella época y comprender sus diversas aportaciones, tanto en materia de creación literaria, como en la valoración de su intervención en las columnas periodísticas. Maria Judite de Carvalho hace desfilar en sus crónicas figuras distintas de mujeres citadinas anónimas, la autora es consciente de su mirada hacia las mujeres, subrayando el retrato de la red urbana desde la perspectiva femenina. Agustina BessaLuís se afirma a través de un carácter más cultural y ensayístico y se ocupa principalmente de la vida del pensamiento. Aunque Agustina demuestra una mirada empática hacia las mujeres, ellas no son tema central en sus crónicas. Sin embargo, la reflexión sobre la condición de la mujer en la sociedad patriarcal, se revela como un tema verdaderamente estructurante en la obra de ficción de la autora, con énfasis en figuras femeninas superiores y no sumisas, complejas y subversivas. En María Teresa Horta, una de sus singularidades cohabita con su estilo sensorial que imprime en su escritura, acentuando el lado femenino y lo erótico y valorando de inmediato una voz femenina en sus crónicas.

Clara Sanz-Hernando de la Universidad de Extremadura en España y Helena Lima de la Universidad de Oporto en Portugal, profundizan en la obra de dos mujeres pioneras en el periodismo durante el franquismo: Pilar Narvión y Concepción López Guerrero. Estas periodistas iniciaron su profesión en una etapa particularmente difícil, la dictadura española. Así las autoras subrayan el marco contextual para centrarse en el periodismo femenino. La trayectoria de las periodistas fue marcada por la dictadura, por la ausencia de libertad de prensa, y también por su condición de mujeres que se abrieron paso en una profesión tradicionalmente masculina. Pilar Narvión fue la primera mujer que trabajó en el diario Pueblo donde se incorporó en los años 50. En el caso de Conchita Guerrero, su ingreso a la actividad periodística se produjo a través de Emilio Romero que, conocedor de las cartas en las que describe su vida en Lisboa, la invitó a desempeñar el puesto de corresponsal de Pueblo, desempeñando dicha labor desde marzo de 1955. Estas periodistas construyen sus carreras en una época en que las 
mujeres alternaban en obediencia a sus padres o a sus maridos. La singularidad de sus situaciones profesionales les proporcionó experiencias diversificadas. De hecho, fue la cobertura de acontecimientos internacionales muy impactantes lo que otorgó gran notoriedad a Narvión. Mientras Conchita Guerrero alcanzó menor repercusión en la última etapa de Pueblo pues la posición que ocupaba contribuyó para que su trabajo fuera menos conocido. En todo caso son dos aportaciones singulares a la historia de la profesión a través de la trayectoria de estas dos periodistas.

Las investigadoras Dunia Etura de la Universidad de Valladolid y Carla Cerqueira de la Universidade Lusófona contribuyen a este monográfico con las trayectorias paralelas de dos periodistas comprometidas con la causa del feminismo. En esta época donde movimientos como el \#Me Too, Time's up o el 8M, han sido determinantes para situar el feminismo en la agenda mediática internacional en los últimos años, las autoras invitan a reconocer a las predecesoras para construir la memoria histórica de las periodistas feministas en la Península lbérica. Así, los inicios de la inclusión del feminismo en los medios de comunicación españoles y portugueses data de los últimos años de las dictaduras de ambos países y preludian la transición no solamente desde la dimensión política sino desde la perspectiva social. Fue entonces cuando las profesionales Carmen Sarmiento y María Antónia Palla comienzan a incluir un enfoque feminista en los contenidos que producen con el fin de trasladar a la ciudadanía un nuevo modelo de mujer basado en la independencia y la igualdad. Las autoras analizan fuentes primarias y el contenido de entrevistas, así como las propias producciones periodísticas de ambas profesionales para evaluar, a la luz de la psicología de las minorías activas (Moscovici, 1981), la capacidad de incorporar a la agenda informativa las temáticas sociales y a las mujeres como sujetos de derechos, la potencialidad para concienciar a la opinión pública en un contexto de transformación democrática y como alternativa generadora de los cambios sociales que se demandaban.

Ana Cabrera, de la Universidad Nova de Lisboa Instituto de História Contemporânea, traza el curso de las grandes luchas de las mujeres en Portugal durante cuarenta años de democracia. En Portugal, el Parlamento ha sido palco de los debates centrales en cuestiones de género e igualdad. Los dos más impactantes han sido la paridad en la representación política y la legalización del aborto. En 1975, la política estaba profundamente masculinizada y los hombres estaban en el centro de las decisiones en todas las esferas de la sociedad. Cuarenta años después, la representación de las mujeres en la Asamblea de la República pasó del 7,6\% al 40\% en 2019, gracias a la aprobación de la ley de paridad de 2006. La lucha por la despenalización del aborto también se prolongó desde 1974 hasta 2007, cuando se aprobó el segundo referéndum. Este ha sido un proceso largo y muy polarizado, con enfrentamiento de posiciones contrarias, dentro y fuera del Parlamento. Los debates parlamentarios sobre estos temas pusieron en manifiesto el olvido de la voluntad y las decisiones de más de la mitad de la sociedad. Además, estos fueron los temas que, a lo largo de más de cuatro décadas, 
involucraron a las mujeres, y que más contribuyeron a la toma de conciencia de su situación frente a una sociedad patriarcal, abriendo puertas a su emancipación y a su empoderamiento.

Javier Jurado de la Universidad de Lille nos propone una reflexión en línea con una historia social de la comunicación, para comprobar si los cambios socio-políticos vienen acompañados por las representaciones comunicativas. Así en el artículo que aporta a este monográfico, investiga sobre las representaciones que TVE difunde de mujeres trabajadoras en las series de ficción durante la tercera legislatura de Felipe González. El periodo 1989-1993, es significativo porque supone la transición desde el modelo institucional de televisión pública al comercial, permitiendo realizar un análisis de las lógicas económicas e industriales en relación a la distribución de roles de género en el mundo laboral mostrado por estas series. Son los años también en los que el Instituto de la Mujer establece el primer Plan para la Igualdad de Oportunidades de las Mujeres (PIOM, 1988-1990) que favorece la integración masiva de las mujeres en el mercado laboral remunerado, esto es, a su "profesionalización". Basándose en los trabajos pioneros de Angela McRobbie, Bev Skeggs y Silvia Walby sobre el establecimiento de las políticas feministas "estatales", este artículo se adentra en las posibles continuidades y rupturas de las divisiones de género y sociales en las producciones de TVE.

Caterina Cucinotta del Instituto de Historia Contemporánea, de la Universidad Nova de Lisboa, señala el análisis convencional del cine y las películas que se construyen a partir de la mirada de los grandes cineastas. Esta estandarización analítica es responsable por el olvido de aspectos considerados menores, pero que son fundamentales en la construcción de la narrativa fílmica. Tanto en España como en Portugal, el departamento que está formado mayoritariamente por mujeres es el diseño de ropa (figurinos o guarda ropa). Como señala la autora, en Portugal este arte se reduce a una función técnica, con salarios y estatus devaluados. Esta investigación, basada en metodologías de historia oral, se centra en cuestiones de género, en las historias de vida de los diseñadores de cine portugueses, jefes de vestuario y costureras. Cronológicamente, el análisis se sitúa entre el inicio de la dictadura de Salazar y finales de los años 90 del siglo XX y aborda simultáneamente la historia y el contexto del cine portugués. En conclusión, la autora valora el trabajo artístico realizado principalmente por mujeres que encabezaban el sector del vestuario y que una sociedad patriarcal no solo las devaluó, sino que las hizo invisibles.

José Luis Torres-Martín y Andrea Castro de la Universidad de Málaga, nos presentan un estudio que contradice el papel subalterno de las mujeres en el mundo audiovisual sobre todo en Andalucía por ser una región periférica respecto a los centros de producción de la industria audiovisual española. Prueba de la excepcionalidad es la trayectoria de Oliva Acosta que inicia su labor en los años 90 dirigiendo documentales en TVE, hasta que creó su propia productora. Pero la producción no fue su primera ocupación. Acosta se 
interesó, además, en esta misma época, por las cuestiones relacionadas con la igualdad de género y fue responsable de Comunicación en la División de Asuntos de Igualdad de la Secretaría de la ONU, en su sede central de Nueva York, entre 1994 y 1999. En este contexto, participó en la organización de la IV Conferencia Mundial de la ONU sobre las Mujeres de Pekín en 1995. Además, su experiencia en cuestiones de igualdad de género es protagonizada por la intervención en proyectos innovadores como WomenWatch y desde Bruselas la Red Internacional de Derechos Humanos de la Mujer, Women's Human Rights Net. Marcada por esta experiencia crea su productora en 2007 y se especializa en la creación y producción de contenidos audiovisuales digitales para cine y televisión.

Isabel Ferin Cunha de la Universidad de Coimbra y del Instituto de Comunicación de la Universidad Nova de Lisboa analiza, desde la triple perspectiva de la Política, el Poder y el Género, las series europeas Borgen (Dinamarca) y Baron Noir (Francia). Enmarca su estudio con una panorámica sobre la ficción política en Portugal y también por las series estadounidense que han iniciado esta modalidad en el género de ficción así como la perspectiva de las mujeres en la trama política, a saber The Good Wife, Scandal y House of Cards. Borgen se emitió entre 2010 y 2013 y está protagonizada por Birgitte Nyborg, candidata de un pequeño partido político que luego se convierte en primera ministra danesa. Baron Noir es una serie francesa (2016-2020) cuyos principales protagonistas son Philipe Rickwaert y Amélie Dorendi, destacados miembros del Partido Socialista francés y candidatos a la presidencia. Las dos obras de ficción se centran en la cobertura mediática y la profesionalización de la política; la complejidad de la toma de decisiones; las contradicciones entre la realpolitik y la moral, así como los desafíos personales que enfrentan los actores políticos, a saber, las mujeres. Ferin nos propone una reflexión sobre la ficción en las plataformas de video bajo demanda que inaugura la nueva televisión. Identifica también similitudes y diferencias entre las dos series en términos de ficción, política y el enfoque del ejercicio del poder basado en el género, a partir de categorías predefinidas e insertas en los principios de la narratología. Ferin Cunha compara los lugares, escenarios y situaciones así como la construcción de los personajes para discutir sobre los referentes de las mujeres políticas y el alcance de la igualdad de oportunidades en la cúspide del poder.

Como podrá observarse, las contribuciones a este monográfico se presentan en orden cronológico y abarcan la aportación de las mujeres a la comunicación desde el siglo XVIII al siglo XXI. El paralelismo histórico en la Península Ibérica y las dictaduras más longevas de Europa marcan, ineludiblemente, los hitos políticos y sociales que afectaron, sobremanera, la vida de las mujeres y sus expectativas personales y colectivas; por eso también puede hacerse una lectura comparada por periodos para destacar los avances republicanos y las expectativas durante las respectivas transiciones. Puede también entenderse este número de la Revista Internacional de Historia de la Comunicación como un itinerario por los escenarios facilitados por los distintos medios de 
comunicación acerca de la construcción de la opinión pública, la agenda política y las subjetividades femeninas y feministas en prensa, cine y televisión, tanto en la información como en la ficción nacional y europea. Quisiéramos también que este número sirviera como homenaje y (re)conocimiento de nuestras predecesoras, para que sus nombres no sean ignorados ni borrados, para que, al contrario, iluminen a las generaciones futuras y auspicien nuevas indagaciones que evidencien con absoluta certeza que todas estas trayectorias -individuales y cruzadas- son argumentos sólidos para restituir la aportación de estas pioneras a la construcción de sociedades democráticas e igualitarias en contextos lastrados por la falta de libertad, de educación y de información. Ellas fueron y son las inspiradoras de un presente más justo.

\section{REFERENCIAS}

Friedan, Betty (2009) La mística de la feminidad. Madrid: Cátedra. (1963) The Feminine Mistique

Lauretis, Teresa de, "Tecnologías de género", en Debate Feminista, no. 2., 1990. (1957), Technologies of Gender. Boomington, Indiana: Indiana Universiy Press.

Sierra Caballero, F. (2008). Sociedad de la información y cultura ibérica. Nuevos horizontes político-culturales. En Comunicación y desarrollo cultural en la Península Ibérica. Retos de la sociedad de la información. Actas del III Congreso Ibérico de Comunicación (15-22), Sevilla: Universidad de Sevilla. 